\title{
CONVENIO SOBRE ARREGLO DE DIFERENCIAS RELATIVAS A INVERSIONES ENTRE ESTADOS Y NACIONALES DE OTROS ESTADOS \\ (CIADI)
}

\author{
CONVENTION OF THE SETTLEMENT OF INVESTMENT DISPUTES BETWEEN \\ STATES AND NATIONALS OF OTHER STATES (ICSID)
}

Gonzalo García Calderón Moreyra*

\section{Resumen}

El artículo explica el funcionamiento del Centro Internacional de Arreglo de Diferencias Relativas a Inversiones entre Estados y nacionales de otros Estados, teniendo en cuenta la importancia de dicho centro en la solución de conflictos hoy en día en el Perú.

Palabras clave: Tratado de Washington de 1965. CIADI. Convenio Arbitral. Árbitros. Procedimiento arbitral.

\begin{abstract}
The article explains the operation of the International Center for Settlement of Investment Disputes between States and nationals of other States, taking into account the importance of this center in the resolution of conflicts in Peru today.
\end{abstract}

Keywords: 1965 Washington Treaty. ICSID. Arbitration Agreement. Referees. Arbitration procedure.

Siempre es importante recordar que el Perú forma parte de la comunidad internacional y se inserta jurídicamente mediante Convenios y/o Tratados, sean estos bilaterales o multilaterales. En materia de comercio exterior tiene celebrados Tratados Bilaterales de Inversión, Tratados de Libre Comercio, además de formar parte de la Organización Mundial

\footnotetext{
* Abogado y Magíster en Derecho Internacional Económico por la Pontificia Universidad Católica del Perú. Fundador y socio de García Calderón Asociados. Miembro de la Comisión Reformadora de la Ley de Títulos y Valores y de la Ley de Arbitraje. Ex director de la Cámara de Comercio de Lima. Arbitro Internacional y Nacional de la lista de la Cámara de Comercio de Lima, de la Pontificia Universidad Católica del Perú, de la Cámara Americana (AMCHAM) y del Organismo de Contrataciones del Estado. Miembro Titular de la Sociedad Peruana de Derecho Internacional.
} 
de Comercio (OMC), de la Comunidad Andina, del Foro de Cooperación Económica Asia Pacífico, entre otros. Gracias a formar parte de este mundo globalizado ha podido recibir inversiones extranjeras de muchísimos países tan alejados no solo físicamente sino jurídicamente como China, Australia, Estados Unidos, entre otros muchos y es natural que puedan surgir conflictos entre el Estado peruano y los nacionales inversores de esos otros Estados, es por ello que la comunidad internacional ha establecido mecanismos comunes transnacionales de solución de controversias.

Para el caso de conflictos que puedan darse entre inversiones efectuadas por nacionales de otros Estados en el Perú y el Estado peruano existe un marco de solución multilateral que permite que neutrales resuelvan dicho conflicto mediante el uso de la conciliación y el arbitraje.

En efecto, el CIADI como se señala en su documento fundacional "fue abierto a la firma de todos los Países miembros del Banco Internacional de Reconstrucción y Fomento el 18 de marzo de 1965. El 14 de octubre de 1966, treinta días después de haber sido depositado en el Banco el vigésimo instrumento de ratificación, el Convenio entró en vigencia de acuerdo con su artículo 68(2)".

Es necesario señalar que se trata de un medio casi universal en la medida que está ratificado por más de 160 países de todos los continentes. Se puede ver la lista de los países miembros en la página web del CIADI ( http://icsid.worldbank.org). El Perú lo firmó el 4 de setiembre de 1991 efectuando el depósito del instrumento de ratificación el 9 de agosto de 1993, entrando en vigencia el 8 de septiembre de 1993.

El Perú ha sido demandado en casi dos docenas de casos desde su vigencia hasta la fecha en materias tan disimiles como inversión en petróleo, energía, gas, minería, electricidad, infraestructura vial, aeroportuaria, portuaria etc. En respuesta a ello, el Estado Peruano ha implementado un Sistema de Coordinación para las controversias internacionales en materia de inversión conocido como SICRESI (creado mediante Ley No 28933 del 15 de diciembre de 2006), el mismo que ha dado muy buenos resultados en la defensa de los intereses nacionales, lo cual incluso, ha merecido un informe favorable de la UNCTAD del año 2011 (Best Practices in investment for development: How to prevent and manage investor-disputes. Lessons from Peru).

Este convenio celebrado por los Estados permite que las controversias sean resueltas de una manera pacífica, dentro del marco de un debido proceso con las garantías de imparcialidad e independencia que se espera de un tribunal de justicia.

\section{Origen y finalidad}


Los inversionistas extranjeros que invierten en el Perú o en cualquier otro Estado, esperan que determinadas reglas legales se respeten mientras dure su inversión, sin embargo muchas veces las reglas de juego son modificadas por los Estados generándose un perjuicio al inversionista que se ve impedido -entre otros ejemplos- de remesar utilidades al exterior, o se establecen tipos de cambio diferenciados, o se aumenta la tasa impositiva, o se generan inconvenientes para acceder a las importaciones o exportaciones de bienes o servicios, o incluso se producen casos de expropiación sean estas expropiaciones de naturaleza directa $o$ indirecta que afectan o perturban el desarrollo de la inversión extranjera en un Estado determinado.

En todos los supuestos antes señalados se genera un conflicto entre InversionistaEstado y ocurre que cuando uno tiene un conflicto con otra persona, sea natural o jurídica, debe ventilarse dicho conflicto ante el Poder Judicial.

Sin embargo, en estos casos de inversión extranjera resulta que el Poder judicial es parte del Estado al cual el inversor extranjero quiere o pretende demandar, por lo que se hace difícil - para el inversionista- creer en la independencia absoluta de un poder de un Estado respecto a otro poder del mismo Estado que adoptó la decisión, sin que pueda existir influencia o presión o nacionalismos que afecten el debido proceso y la seguridad jurídica que se espera.

Es por ello que históricamente en muchas ocasiones el inversionista extranjero recurría a la protección diplomática o a reclamaciones del Estado del inversionista para que presione diplomáticamente al Estado receptor de la inversión, llegándose incluso al uso de la fuerza.

La finalidad u objetivo del CIADI mediante este mecanismo de solución de conflictos es pues, permitir someter la controversia a un tribunal imparcial ajeno al domicilio del Estado receptor de la Inversión y de preferencia con árbitros de nacionalidad distinta a los involucrados, bajo el manto de una institución prestigiosa como lo es el Banco Mundial, desarrollándose dentro de un procedimiento que garantice un trato igualitario tanto a inversionistas como a los Estados y que las decisiones tengan el carácter de cosa juzgada.

El propio convenio establece en su artículo 27 que "Ningún Estado Contratante concederá protección diplomática ni promoverá reclamación internacional respecto de cualquier diferencia que unos de sus nacionales y otro Estado contratante hayan consentido en someter o hayan sometido a arbitraje conforme a este convenio, salvo que este último Estado no haya acatado el laudo dictado en tal diferencia o haya dejado de cumplirlo".

\section{Competencia}


Qué duda cabe que este foro es consciente que debe limitar la competencia del Centro estableciéndose que sólo se someterán las diferencias surgidas de una inversión efectuada por un nacional extranjero de un país miembro y un Estado miembro receptor de dicha inversión. (Es necesario mencionar que, además de este convenio que se está analizando, existe un Reglamento denominado mecanismo complementario del CIADI para brindar servicios de conciliación y arbitraje a aquellos nacionales de otros Estados no miembros).

El tema competencial es un tema recurrente en los arbitrajes bajo administración del centro respecto a las excepciones que se pueden plantear con relación a la competencia del CIADI, sea en razón de la nacionalidad de las partes, sea en razón de la vigencia de la aplicación en el tiempo del sometimiento al CIADI y/o incluso sobre si se trata o no de una materia que debe ser considerada o no como una inversión.

Estas excepciones en razón de, la temporalidad, de la materia y en razón de la persona involucrada, son utilizadas como medio de defensa en muchas ocasiones por los Estados. El Estado Peruano ha utilizado todas estas excepciones en gran parte de sus casos, citaré algunos de ellos pero por razones de espacio no podré desarrollarlos:

i) Industria Nacional de Alimentos S.A. e Idelsa Perú S.A vs República del Perú.

ii) Duke Energy International vs República del Perú.

iii) Tza Yap Shum vs República del Perú.

iv) Convial Callao S.A. vs República del Perú.

v) Renee Rose Levy vs República del Perú.

vi) DP World Callao vs República del Perú.

vii) Lidercom vs República del Perú.

viii) Gramercy funds Mangement LLC vs República del Perú.

El centro puede, al igual que sucede en la mayoría de reglamentos de las instituciones arbitrales de carácter comercial, rechazar liminarmente la solicitud si considera que no existe convenio arbitral o sometimiento válido a la competencia del centro para conocer de la controversia. Esta decisión "Prima Facie" solo versa sobre la competencia del centro, ya que la competencia referida a las materias o nacionalidad o temporalidad serán resueltas por el propio tribunal arbitral bajo el principio del "KOMPETENZ KOMPETENZ" o competencia de los árbitros para resolver sobre su propia competencia.

En efecto el inciso (3) del artículo 36 señala que "El secretario General registrará la solicitud salvo que, de la información contenida en dicha solicitud, encuentre que la diferencia se halla manifiestamente fuera de la jurisdicción del centro. Notificará inmediatamente a las partes el acto de registro de la solicitud, o su denegación. Este artículo debe concordarse con el artículo 41 (1) del Convenio el cual señala que "El tribunal resolverá sobre su propia competencia". 


\section{Conciliación}

Solo para comentar de manera muy rápida que el Centro cuenta con un capítulo previo al arbitraje denominado de la Conciliación, para permitir a las partes arribar a un acuerdo negociado con el apoyo del centro. No es un paso previo o escalonado anterior al arbitraje, salvo que las partes lo hayan pactado de esa manera.

Muy similar a lo que ocurre en nuestro país con la Ley de Conciliación extrajudicial (Decreto Legislativo 1070) en donde el Estado no le ha dado el carácter de obligatorio a la Conciliación, previo al arbitraje, como sí lo ha hecho para determinadas materias que deben ser resueltas en el ámbito judicial, las cuales requieren, antes de acudir al órgano judicial competente, previamente, el inicio de un proceso de conciliación ante un centro de conciliación acreditado ante el Ministerio de Justicia, para solo en caso de no llegar a un acuerdo satisfactorio, acudir al Poder judicial.

Se trata de un mecanismo, según lo disponen las reglas del Centro -salvo acuerdo en contrario de las partes- en donde actuarán tres conciliadores: uno designado por cada parte y el tercero designado de común acuerdo por los dos conciliadores, y en caso de no existir acuerdo, por el centro. Esta comisión de conciliadores debe estar integrada por personas de "amplia consideración moral, tener reconocida competencia en el campo del Derecho, del comercio, de la industria, o de las finanzas, e inspirar plena confianza en su imparcialidad y juicio".

La comisión podrá proponer fórmulas de acuerdo las veces que consideren necesario efectuarlo y lógicamente no se levantará un acta de lo acontecido en las reuniones, solo se levantará el acta dejando constancia de si se llegó o no a un acuerdo. Es fundamental que las partes tengan la libertad de poner sobre la mesa todas las opciones sin que ello signifique reconocimiento alguno, por lo que nada de lo que se discuta, oferte o declare al interior de la comisión puede ser utilizado luego en el procedimiento arbitral.

\section{El Arbitraje}

Este procedimiento se inicia con una solicitud que debe ser dirigida por escrito al Secretario General donde se deberá indicar una breve descripción del conflicto, las generales de ley de las partes, las reclamaciones, el contrato o convenio del que emana o deriva su derecho a la competencia del centro, en la medida que -como en todo arbitraje- y este no es la excepción, se requiere el consentimiento de las partes para el sometimiento a este mecanismo de solución de conflictos.

El convenio señala que las partes podrán señalar si desean árbitro único o tribunal arbitral, pero si no lo deciden, este se compondrá de tres árbitros, cada parte elegirá a uno y 
entre estos elegirán al presidente del tribunal arbitral. En caso de no llegar a un acuerdo, la designación correrá a cuenta del Presidente del Consejo de administración del centro.

El Tribunal arbitral es el único competente para resolver o decidir sobre su propia competencia, sobre las excepciones de cualquier naturaleza (cosa juzgada, caducidad, incompetencia), sobre la inexistencia, nulidad o ineficacia del convenio arbitral o sobre la arbitrabilidad de la materia o sobre cualquier otro tema que busque impedir el conocimiento sobre el fondo del conflicto.

Sin duda el arbitraje depende en gran medida de los árbitros que conforman el tribunal arbitral.

Como ocurre en todo proceso donde un tercero debe resolver un conflicto, este debe ser neutral frente a las partes, es decir, debe ser imparcial e independiente respecto de ellas, sus abogados, representantes, auditores y cualquier relación directa o indirecta que pueda poner en duda su actuación. La independencia tiene un carácter objetivo, como alguna relación de parentesco, dependencia laboral, financiera, amical, entre otros; mientras que la imparcialidad tiene que ver con un carácter subjetivo del árbitro, una predisposición, una inclinación, un prejuicio.

Es importante tener en consideración lo que señala el convenio del CIADI en la Regla 6 aplicable a los procedimientos de arbitraje, al señalar que cada árbitro una vez designado debe emitir una declaración cuyo texto es el siguiente:

“A mi leal saber y entender no hay razón alguna por la que no deba servir en el tribunal de arbitraje constituido por el Centro Internacional de Arreglo de Diferencias relativas a Inversiones con respecto a la diferencia entre .... y....”.

"Me comprometo a mantener con carácter confidencial toda la información que llegue a mi conocimiento a consecuencia de mi participación en este proceso, así como del contenido de cualquier laudo que este tribunal dicte." "Juzgare con equidad, de acuerdo con la ley aplicable y no aceptaré instrucción o compensación alguna de ninguna otra fuente con respecto al procedimiento, salvo según lo dispuesto en el Convenio sobre Arreglo de Diferencias relativas a Inversiones sobre Estados y Nacionales de otros Estados y en los Reglamentos y reglas adoptadas de conformidad con el mismo". "Adjunto una declaración sobre mi experiencia profesional, de negocios y otras relaciones (de haberlas) con las partes, tanto anteriores como actuales".

En toda declaración debe revelarse todas las circunstancias que puedan dar lugar a dudas sobre la imparcialidad o independencia del árbitro, tales como vinculación con las partes, con la controversia, con los abogados de las partes, con los demás co-arbitros, con otras personas implicadas en el arbitraje, para ello existen diversas fuentes de referencia para tomar en consideración sobre que se debe revelar o cuando no se puede aceptar el cargo de árbitro como las reglas de la International Bar Association o el Código de Buenas prácticas 
arbitrales del club español de arbitraje por mencionar algunas prácticas internacionales o las reglas éticas de la Cámara de Comercio de Lima por mencionar una referencia nacional.

Como es natural, si alguna de las partes considera que existe alguna duda justificada para dudar de la independencia o imparcialidad del árbitro deberá señalarlo, para lo cual tiene expedito su derecho de solicitar la recusación de un árbitro, el que será resuelto por los otros miembros del colegiado.

\section{Procedimiento Arbitral}

La flexibilidad del procedimiento arbitral permite a las partes y en defecto de ellas, a los árbitros, fijar lo relativo a los plazos, reglas de presentación, actuación de pruebas entre otras. Esta libertad para fiar las reglas del procedimiento va de la mano con la autonomía de las partes para elegir las características de los árbitros, la libertad para elegir el tipo de arbitraje que desean, es decir si consideran más adecuado un arbitraje de conciencia o equidad o un arbitraje de derecho, siempre manteniendo el mismo derecho para ambas partes.

La finalidad de todo procedimiento es que las partes puedan exponer, sustentar sus alegaciones, ser escuchados, por los árbitros, para lo cual se podrán presentar memorias, contramemorias y las pruebas que consideren pertinentes, dentro de los plazos que serán determinados por el tribunal arbitral, previa coordinación con las partes.

La regla procesal aplicable a los procedimientos de arbitraje del Centro prescribe que, salvo pacto en contrario, el procedimiento comprenderá dos etapas distintas: una etapa dedicada a las actuaciones escritas y una segunda etapa dedicada a las actuaciones orales. Esta programación de las sesiones corresponderá fijarlas al tribunal arbitral.

Obviamente el Tribunal arbitral tiene la facultad de solicitar pruebas de oficio, e incluso de incorporar a los denominados "Amicus Curiae" o amigos del tribunal a efectos que expongan y permitan al tribunal tener todos los elementos de convicción para mejor resolver.

El artículo 42 del Convenio prescribe que "El Tribunal decidirá la diferencia de acuerdo con las normas de derecho acordadas por las partes. A falta de acuerdo, el Tribunal aplicará la legislación del Estado que sea parte en la diferencia, incluyendo sus normas sobre Derecho Internacional Privado, y aquellas normas de Derecho Internacional que pudieran ser aplicables".

Es bueno recordar que la existencia del Derecho Internacional Privado tiene por objeto resolver conflictos que se presentan en una relación jurídica donde existen dos o más elementos extranjeros relevantes. En la medida que dos partes tengan sus domicilios en Estados diferentes y no hayan establecido el derecho que regulará dicha controversia, se deberá buscar el mejor Derecho y ello se efectuará mediante factores de conexión, que 
determinarán el derecho aplicable. Las normas que regularán el factor de conexión a aplicar serán las del Estado en controversia según lo prescrito en este artículo 42.

\section{Laudo, revisión y anulación}

El resultado final de todo procedimiento es la emisión del laudo arbitral, es el objetivo de la designación de los árbitros, es la solución final del conflicto entre las partes y el cumplimento de la labor encomendada a los Árbitros.

El Laudo arbitral debe contener un resumen de los hechos, debe existir una motivación de los árbitros a la luz de las pruebas ofrecidas por las partes y actuadas en el desarrollo del proceso y debe existir una resolución sobre cada uno de los problema o controversias sometidas a la decisión de los árbitros, la cual tendrá el carácter de cosa juzgada.

Al igual que en el arbitraje comercial el procedimiento arbitral es instancia única y no cabe revisión sobre el fondo de la controversia. Sin embargo, hay una excepción -que no se encuentra regulada en nuestra legislación- denominada solicitud de Revisión del Laudo:

El artículo 51 del convenio señala "Cualquiera de las partes podrá pedir, mediante escrito dirigido al Secretario General la revisión del Laudo, fundada en el descubrimiento de algún hecho que hubiera podido influir, decisivamente en el laudo, y siempre que, al tiempo de dictarse el laudo, hubiera sido desconocido por el tribunal y por la otra parte que inste la revisión y que el desconocimiento de ésta no se deba a su propia negligencia”.

Tiene un plazo máximo de 90 días para solicitarse desde que se descubrió el hecho y un plazo de caducidad de 3 (tres) años de dictado el laudo y deberá ser resuelto por el mismo tribunal arbitral que dicto el laudo, en la medida de lo posible, de lo contrario se constituirá otro tribunal arbitral.

En cuanto a la Anulación del laudo, es una solicitud que busca salvaguardar la tutela procesal efectiva, se trata de cuestiones de forma, sin entrar a la motivación, ni a los criterios que tuvieron los árbitros al momento de laudar, se busca cautelar el debido proceso, básicamente lo que se busca es proteger a las partes del abuso de los árbitros, de la violación de algún derecho fundamental que haga inviable la ejecución del laudo.

Las causales de anulación de laudo son por los siguientes hechos:

i) una constitución incorrecta del tribunal arbitral;

ii) que el tribunal falló más allá de lo solicitado por las partes extralimitando sus facultades;

iii) que haya existido algún caso de corrupción sobre uno de los miembros del tribunal; 
iv) que se haya quebrantado de manera grave una norma de procedimiento;

v) o que no exista motivación del laudo.

Estas causales de anulación deberán ser presentadas dentro de los 120 días siguientes de dictado el laudo, salvo la causal de corrupción que cuenta con un plazo de tres años para ser invocada desde la fecha de emitido el laudo. En estos casos se constituirá una comisión ad hoc integrada por tres personas seleccionadas de la lista de árbitros que cuenta el Centro. La comisión resolverá declarando fundada o infundada la solicitud de anulación de laudo arbitral, pudiendo incluso ordenar la suspensión provisional de la ejecución del laudo hasta emitir su decisión.

En caso de declararse fundada la anulación, deberá integrarse un nuevo tribunal arbitral que revisará la controversia.

\section{Reconocimiento Ejecución de Laudo}

La idea de este convenio es que todo laudo arbitral dictado al amparo del Convenio CIADI se ejecute dentro de los territorios de los Estados miembros sin necesidad de llevar adelante un reconocimiento de sentencia o laudo arbitral emitido en el extranjero, conocido como el nombre de Exequatur.

En efecto, doctrinariamente, por un tema de territorialidad, cualquier sentencia judicial o laudo arbitral que es dictado en el exterior, requiere una revisión formal por parte del Estado en donde pretende ejecutarse dicha decisión.

Lo que se busca mediante el exequatur es que la decisión dictada en un territorio distinto al que se quiere ejecutar, previamente cumpla con un reconocimiento de determinadas seguridades y garantías jurídicas que el Estado receptor de la sentencia o laudo considera que deben cumplir todas aquellas decisiones que provengan de un país extranjero.

Entre los temas que el país receptor efectúa respecto de la decisión emitida en el exterior, es por ejemplo revisar si el tribunal extranjero que conoció el conflicto era competente para abocarse al conocimiento de dicho caso; si la materia no es de competencia exclusiva de los tribunales nacionales; si se cumplió con el debido proceso entendido como si se le dio un plazo suficiente para comparecer; si contó con abogado, si tuvo garantías para contradecir, ser escuchado; si la materia no viola asuntos de orden público internacional entre otros temas, que para el caso del Perú, se encuentran regulados en el artículo 2102 y siguientes del Código Civil. Digamos que se busca que cumpla con un test de legalidad.

Lo novedoso de este Convenio es que los países firmantes se comprometen a ejecutar las sentencias dictadas al amparo del tratado de Washington de 1965 sin necesidad de llevar adelante exequatur alguno, es decir que todo Estado contratante hará ejecutar dentro de su 
territorio las obligaciones impuestas en el Laudo como si se tratare de una sentencia firme dictada por un tribunal existente en dicho Estado.

\section{Conclusiones}

1) El Convenio sobre Arreglo de Diferencias Relativas a Inversiones entre Estados y Nacionales de otros Estados (Convention of the Settlement of Investment disputes between States and National of other States) tiene por objeto la cooperación internacional para el desarrollo económico mediante la solución de conflictos que se presenten en materia de inversiones entre Estados y nacionales de otros Estados.

2) Se le conoce como convenio de Washington de 1965, siendo actualmente el referente para las soluciones en materia de inversión extranjera.

3) Bajo el auspicio del Banco Mundial el convenio crea el Centro Internacional de Arreglo de Diferencias relativas a Inversiones, el cual cuenta con un Consejo Administrativo compuesto por un representante de cada uno de los Estados contratantes.

4) El Consejo Administrativo se reúne cuando menos una vez por año y cuenta con un Secretario General además de varios secretarios adjuntos, siendo el Secretario General el representante legal y principal funcionario del Centro.

5) El Centro cuenta con un Reglamento Procesal para la Conciliación y el Arbitraje.

6) La jurisdicción del centro se aplica a inversiones entre un Estado contratante y nacionales de otro Estado contratante, entendiéndose como nacional de otro Estado a toda persona natural que tenga en la fecha en que las partes consintieron someter la controversia a conciliación o arbitraje, la nacionalidad de un Estado contratante distinto del Estado parte en la controversia. En ningún caso aplica para los nacionales del mismo Estado. 